\title{
Genetic studies of laboratory reared Mytilus edulis. II. Selection at the leucine amino peptidase (Lap) locus
}
A. R. Beaumont,
C. M. Beveridge,
E. A. Barnet and
M. D. Budd

School of Ocean Sciences, University College of North Wales, Menai Bridge, Gwynedd LL59 5EH, U.K.

Offspring from several families and a mass mating of Mytilus edulis were cultured in the laboratory up to the juvenile stage under different temperature regimes. Mussels were genotyped at the leucine aminopeptidase (Lap) locus at the spat stage (post-metamorphosis) using cellulose acetate electrophoresis and at the juvenile stage using starch gel electrophoresis. Significant deviations from expected genotype frequencies were found in many cultures at both stages and certain genotypes were generally found to be favoured irrespective of temperature regime during culture. Estimates of relative fitnesses of the six common $L a p$ genotypes suggest overdominance for the alleles $\operatorname{Lap}^{94}$ and $L_{a p}{ }^{96}$ and semi-dominance for $\operatorname{Lap}^{98}$, but calculations based on this array of estimated fitnesses indicate that $L a p^{98}$ would eventually become fixed in a panmictic population. Since a balanced Lap polymorphism exists in the wild we conclude that selection differentials at the Lap locus in laboratory cultures may be very different from those in nature, and suggest that nutritional constraints may account for some of these differences in selection. Also, in contrast to wild populations, the laboratory cultures showed a significant excess of Lap heterozygotes.

\section{INTRODUCTION}

The leucine aminopeptidase (Lap) locus which codes for an $\alpha$-aminoacylpeptide hydrolase (Young et al., 1979) in Mytilus edulis has been extensively studied in recent years (for reviews see Levinton and Koehn, 1976; Koehn, 1985; Hilbish and Koehn, 1985). Five Lap alleles have been detected, although only three are common in any one area (Levinton and Koehn, 1976). In UK waters and on the eastern coast of America, south of Cape Cod, $\operatorname{Lap}^{94}, \operatorname{Lap}^{96}$, and $\operatorname{Lap}^{98}$ are the commonest alleles (Koehn et al., 1976; Skibinski et al., 1983; Ahmad and Hedrick, 1985). In Long Island Sound, New York, there is a cline in the frequency of $L a p^{94}$ that is associated with changes in salinity along the Sound. Under varying salinities, biochemical differences in Lap allozymes produce genotype specific rates of change in the free amino acid pool which is an important element in cell volume regulation (Hilbish et al., 1982). In a detailed study of this cline, Hilbish and Koehn (1985) concluded that a high degree of dominance existed for the biochemical and physiological phenotypic expression of $\operatorname{Lap}^{94}$ genotypes and that a selection model incorporating dominance gave a close fit to observed Lap genotype frequencies among natural populations in the cline.

This paper reports on genotype specific mortalities at the Lap locus in offspring from a number of families and a mass mating of $M$. edulis which were reared in the laboratory at different temperatures but at constant salinity. Evidence is provided for selection at the Lap locus, and estimates are made of the relative fitnesses of Lap genotypes.

\section{MATERIALS AND METHODS}

Ripe $M$. edulis were collected in the Menai Strait, North Wales, UK, during 1984 and 1985 and cultures of larvae were reared as described by Beaumont et al. (1988). Larvae and juveniles from several families (M1, M2, M3 and M4) and a mass mating (MM) were cultured under a number of temperature regimes. The temperature regime used for each culture is indicated in tables 1-4. Samples for electrophoresis were taken at the spat stage $(500-1000 \mu \mathrm{m})$ in all cultures, and again at the 
juvenile stage in some of the cultures. Techniques for cellulose acetate microelectrophoresis of spat, starch gel electrophoresis of juveniles and staining for Lap are detailed in Beaumont et al. (1988).

Expected Lap genotype and allele frequencies in the offspring from single families were calculated from the known genotypes of the parents. Expected genotype and allele frequencies for the mass mating were calculated on the assumption of equal and random mixing of all gametes from the 15 mussels (nine males, six females) spawned. Evidence for equal gametic contribution of all progenitors in this mass mating are presented in a previous paper (Beaumont et al., 1988). Deviations of observed from expected genotype and allele frequencies were tested for significance using the $\chi^{2}$ goodness of fit test.

\section{RESULTS}

Lap genotype and allele frequencies are shown for family $\mathrm{M} 2$ in table 1 . In almost every sample taken from cultures in this family, regardless of temperature and age, heterozygous Lap ${ }^{94 / 96}$ individuals were significantly more frequent than expected. The frequency of the $L a p^{94}$ allele was therefore significantly higher than expected in most samples. Four Lap genotypes, each expected at equal frequency, were present in family M3 and their observed frequencies in all M3 cultures are given in table 2. Irrespective of temperature or age at sampling, the $L_{a p^{94 / 96}}$ heterozygote was again significantly more frequent than expected, and in most cases this was also true of the $L a p^{94 / 98}$ genotype. Too few $L a p^{96 / 96}$ homozygotes and Lap ${ }^{96 / 98}$ heterozygotes were observed. Allele frequencies reflect the high abundance of $\operatorname{Lap}^{94 / 96}$ and $L a p^{94 / 98}$ individuals with the $\operatorname{Lap}^{94}$ allele generally being significantly more frequent than expected.

Lap genotype and allele frequencies in samples of spat from cultures of families M1 and M4 were not in disagreement with expected frequencies (table 3). Data from samples taken principally at the spat stage in the mass mating (MM) cultures are presented in table 4 . In most samples, observed genotype and allele frequencies differ significantly from those predicted. The genotypes $\operatorname{Lap}^{94 / 96}$, $L a p^{94 / 98}$ and $L a p^{98 / 98}$ are generally more common than expected while the Lap ${ }^{96 / 96}$ genotype is deficient in every culture sampled. No clear trends were evident with regard to the temperature at which the cultures were held. Allele frequency data reveal that the $L a p^{94}$ and $L a p^{98}$ alleles are generally more common, and the $L a p^{96}$ allele always less common than predicted.

Table 5 details the numbers of samples over all families and the mass mating in which the observed frequencies of the various Lap genotypes were either greater than, or less than the expected frequencies. If mortalities are random with respect

Table 1 Genotype and allele frequencies at the Lap locus in Family M2 of Mytilus edulis sampled at the spat and juvenile stages and reared at different temperatures

\begin{tabular}{|c|c|c|c|c|c|c|c|}
\hline \multirow{3}{*}{$\begin{array}{l}\text { Expected } \\
\text { frequencies }\end{array}$} & & \multicolumn{3}{|c|}{ Genotype frequencies } & \multicolumn{3}{|c|}{ Allele frequencies } \\
\hline & & $94 / 96$ & $96 / 96$ & \multirow[b]{2}{*}{$x^{2}$} & \multirow{2}{*}{$\frac{94}{0 \cdot 250}$} & \multirow{2}{*}{$\frac{96}{0 \cdot 750}$} & \multirow[b]{2}{*}{$\chi^{2}$} \\
\hline & & $0 \cdot 500$ & $0 \cdot 500$ & & & & \\
\hline A $[15,15]$ & $\begin{array}{l}\text { Spat } \\
\text { Juvenile }\end{array}$ & $\begin{array}{l}0.793(46) \\
0.628(64)\end{array}$ & $\begin{array}{l}0 \cdot 207(12) \\
0 \cdot 373(38)\end{array}$ & $\begin{array}{l}* * * \\
*\end{array}$ & $\begin{array}{l}0 \cdot 397 \\
0 \cdot 314\end{array}$ & $\begin{array}{l}0.603 \\
0.686\end{array}$ & $\begin{array}{l}* * * \\
*\end{array}$ \\
\hline $\mathrm{B}[15,22]$ & $\begin{array}{l}\text { Spat } \\
\text { Juvenile }\end{array}$ & $\begin{array}{l}0.750(45) \\
0.610(61)\end{array}$ & $\begin{array}{l}0.250(15) \\
0 \cdot 390(39)\end{array}$ & $\begin{array}{l}* * * \\
*\end{array}$ & $\begin{array}{l}0 \cdot 375 \\
0 \cdot 305\end{array}$ & $\begin{array}{l}0.625 \\
0.695\end{array}$ & $\begin{array}{l}* * \\
\mathrm{~ns}\end{array}$ \\
\hline$C[22,15]$ & $\begin{array}{l}\text { Spat } \\
\text { Juvenile }\end{array}$ & $\begin{array}{l}0 \cdot 660(33) \\
0 \cdot 500(51)\end{array}$ & $\begin{array}{l}0 \cdot 340(17) \\
0 \cdot 500(51)\end{array}$ & $\begin{array}{l}* \\
\mathrm{~ns}\end{array}$ & $\begin{array}{l}0 \cdot 330 \\
0 \cdot 250\end{array}$ & $\begin{array}{l}0.670 \\
0.750\end{array}$ & $\begin{array}{l}\text { ns } \\
\text { ns }\end{array}$ \\
\hline $\mathrm{D}[22,22]$ & $\begin{array}{l}\text { Spat } \\
\text { Juvenile }\end{array}$ & $\begin{array}{l}0.667(38) \\
0.696(71)\end{array}$ & $\begin{array}{l}0 \cdot 333(19) \\
0 \cdot 304(31)\end{array}$ & $\begin{array}{l}* \\
* * *\end{array}$ & $\begin{array}{l}0 \cdot 333 \\
0 \cdot 348\end{array}$ & $\begin{array}{l}0.667 \\
0.652\end{array}$ & $\begin{array}{l}* \\
* *\end{array}$ \\
\hline
\end{tabular}

Numbers in round brackets are sample sizes. Temperature regimes for each culture are given in square brackets; the first figure represents the temperature $\left({ }^{\circ} \mathrm{C}\right)$ before sampling at the spat stage, the second, the temperature after spat were sampled.

$*=P<0.05$.

$* *=P<0.01$.

$* * *=P<0.001$.

$\mathrm{ns}=$ not significant. 
Table 2 Genotype and allele frequencies at the Lap locus in Family M3 of Mytilus edulis, sampled at the spat and juvenile stages and reared at different temperatures. For full details see table 1

\begin{tabular}{|c|c|c|c|c|c|c|c|c|c|c|}
\hline \multirow{2}{*}{$\begin{array}{l}\text { Expected } \\
\text { frequencies }\end{array}$} & & \multicolumn{5}{|c|}{ Genotype frequencies } & \multicolumn{4}{|c|}{ Allele frequencies } \\
\hline & & $94 / 96$ & $94 / 98$ & $96 / 96$ & $96 / 98$ & $\chi^{2}$ & 94 & 96 & 98 & $\chi^{2}$ \\
\hline & Spat & $0.343(34)$ & $0.202(20)$ & $0 \cdot 313(31)$ & $0 \cdot 141(14)$ & * & $0 \cdot 273$ & 0.555 & $0 \cdot 172$ & $*$ \\
\hline $\mathrm{B}[15,22]$ & Juveniles & $0 \cdot 451(46)$ & $0 \cdot 333(34)$ & $0.137(14)$ & $0.078(8)$ & $* * *$ & $0 \cdot 392$ & 0.402 & $0 \cdot 206$ & $* * *$ \\
\hline $\mathrm{C}[22,15]$ & Juveniles & $0.549(56)$ & $0 \cdot 343(35)$ & $0.088(9)$ & $0.020(2)$ & $* * *$ & 0.446 & $0 \cdot 373$ & $0 \cdot 181$ & $* * *$ \\
\hline & Spat & $0 \cdot 365(35)$ & $0.354(34)$ & $0 \cdot 167(16)$ & $0 \cdot 115(11)$ & $* * *$ & 0.359 & 0.406 & 0.235 & $* *$ \\
\hline $\mathrm{D}[22,22]$ & Juveniles & $0.500(51)$ & $0 \cdot 373(38)$ & $0.059(6)$ & $0.069(7)$ & $* * *$ & 0.436 & $0 \cdot 343$ & $0 \cdot 221$ & $* * *$ \\
\hline
\end{tabular}

Table 3 Genotype and allele frequencies at the Lap locus in families M1 and M4 of Mytilus edulis, sampled at the spat and juvenile stages and reared at different temperatures. For full details see table 1

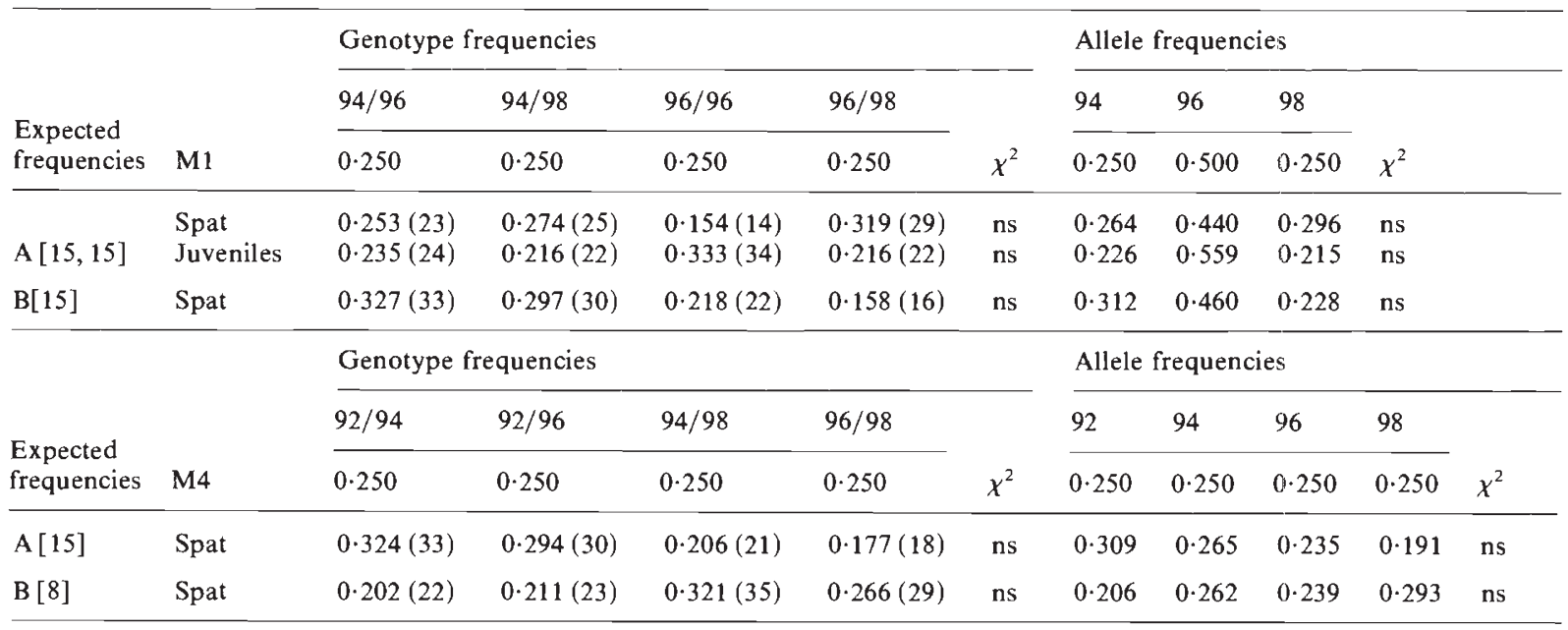

Table 4 Genotype and allele frequencies at the Lap locus in a mass mating of Mytilus edulis sampled at the spat and juvenile stages and reared at different temperatures. For full details see table 1

\begin{tabular}{|c|c|c|c|c|c|c|c|c|c|c|c|c|}
\hline \multicolumn{2}{|c|}{$\begin{array}{l}\text { Expected } \\
\text { frequencies }\end{array}$} & $96 / 98$ & $96 / 96$ & $94 / 96$ & $98 / 98$ & $94 / 98$ & $94 / 94$ & & 94 & 96 & 98 & \\
\hline $\mathrm{A}[15]$ & Spat & $0 \cdot 375(39)$ & $0 \cdot 289(30)$ & $0.096(10)$ & $0 \cdot 154(16)$ & $0.067(7)$ & $0.019(2)$ & $\mathrm{ns}$ & $0 \cdot 101$ & 0.524 & 0.375 & ns \\
\hline $\mathrm{D}[8]$ & Spat & $0.333(35)$ & $0 \cdot 200(21)$ & $0 \cdot 200(21)$ & $0.086(9)$ & $0 \cdot 152(16)$ & $0.029(3)$ & $* * *$ & 0.205 & 0.467 & 0.328 & $* * *$ \\
\hline$E[15,15]$ & $\begin{array}{l}\text { Spat } \\
\text { Juvenile }\end{array}$ & $\begin{array}{l}0.230(26) \\
0.218(17)\end{array}$ & $\begin{array}{l}0.274(31) \\
0.295(23)\end{array}$ & $\begin{array}{l}0.274(31) \\
0.154(12)\end{array}$ & $\begin{array}{l}0 \cdot 106(12) \\
0 \cdot 192(15)\end{array}$ & $\begin{array}{l}0 \cdot 115(13) \\
0 \cdot 103(8)\end{array}$ & $\begin{array}{l}0.000(0) \\
0.039(3)\end{array}$ & $\begin{array}{l}* * * \\
* * *\end{array}$ & $\begin{array}{l}0 \cdot 195 \\
0 \cdot 167\end{array}$ & $\begin{array}{l}0.527 \\
0.481\end{array}$ & $\begin{array}{l}0.279 \\
0.353\end{array}$ & $\begin{array}{l}* * * \\
*\end{array}$ \\
\hline$F[15]$ & Spat & $0.442(46)$ & $0 \cdot 164(17)$ & $0.192(20)$ & $0 \cdot 125(13)$ & $0.077(8)$ & $0.000(0)$ & $* *$ & $0 \cdot 135$ & 0.481 & 0.385 & $*$ \\
\hline
\end{tabular}


Table 5 Numbers of samples of cultures of spat or juvenile Mytilus edulis reared in the laboratory in which observed Lap genotype frequencies are higher than, or lower than expected frequencies. Genotypes Lap $^{92 / 94}$ and Lap ${ }^{92 / 96}$ are not included because these genotypes were only present in two cultures. Under the null hypothesis of equal occurrences of frequencies above or below expectations, the sign test compares the ratio of instances higher than or lower than expected frequencies for each genotype.

\begin{tabular}{|c|c|c|c|c|c|c|}
\hline \multirow[t]{2}{*}{ Homozygotes } & $94 / 94$ & 7 & 4 & - & 3 & ns \\
\hline & $98 / 98$ & 7 & 6 & - & 1 & $\mathrm{~ns}$ \\
\hline \multirow[t]{2}{*}{ Heterozygotes } & $94 / 96$ & 24 & 21 & 1 & 2 & $* *$ \\
\hline & $94 / 98$ & 18 & 14 & - & 4 & $*$ \\
\hline
\end{tabular}

$*=P<0.05$.

$* *=P<0.01$.

ns $=$ non-significant.

Table 6 Numbers of samples of cultures of spat or juvenile Mytilus edulis reared in the laboratory in which observed Lap allele frequencies are higher than or lower than expected frequencies. Lap ${ }^{92}$ is not included. For details of sign test see table 5.

\begin{tabular}{lllllr}
\hline Allele & Number of samples & $\begin{array}{l}\text { Number above } \\
\text { expected frequency }\end{array}$ & $\begin{array}{l}\text { Number equal to } \\
\text { expected frequency }\end{array}$ & $\begin{array}{l}\text { Number below } \\
\text { expected frequency }\end{array}$ \\
\hline Lap $^{94}$ & 26 & 23 & 1 & 2 & 21 \\
Lap $^{96}$ & 26 & 4 & 1 & 10 & $* *$ \\
Lap $^{98}$ & 18 & 8 & - & $n$ \\
\hline
\end{tabular}

$*=P<0 \cdot 05$.

** $=P<0.01$.

ns $=$ non-significant.

to Lap genotypes then equal numbers of samples would be expected to show higher than, or lower than, expected genotype frequencies. The number of instances where observed frequencies are higher than, or lower than expected are tested using the sign test (Sokal and Rohlf, 1981). The genotypes $L a p^{94 / 96}$ and $L a p^{94 / 98}$ occurred at a higher frequency than expected in significantly more than half of the samples, while the reverse was true for the $L a p^{96 / 98}$ and $L a p^{96 / 96}$ genotypes. In table 6 the Lap allele frequency data is tested against the same hypothesis that equal numbers of samples should show higher or lower frequencies than expected. $L a p^{94}$ frequencies were higher than expected in significantly more than half the samples and this was balanced principally by reduced frequencies of $L a p^{96}$, but not $L a p^{98}$.

\section{DISCUSSION}

Because we have used single pair, or restricted matings we can be sure that deviations from expected genotype frequencies are not due to the Wahlund effect. Moreover, bearing in mind the dispersal potential of mussels, it is extremely unlikely that any of the adults used in our trials were closely related and inbreeding effects can therefore also be discounted. Deviations from expected genotype frequencies in wild populations can be produced by the presence of null alleles. However, only one parent from one of the single families (M2) could possibily have been heterozygous for a null allele (all others were heterozygous for known Lap alleles) and this would have resulted in some M2 offspring appearing to be Lap $^{94}$ homozygotes. No such offspring were observed in that family. Null alleles could have gone undetected in the mass mating, but, in more extensive studies of $M$. edulis, no evidence, has been found for the existence of null Lap alleles (Koehn et al., 1976; Skibinski et al., 1983).

We conclude therefore that the Lap genotype specific mortalities observed are most likely due to selection. However, it is important to establish whether selection is occurring at the Lap locus or at other linked loci. In the case of a single family, electrophoretically detected loci may act as markers for much of, or entire chromosomes. However, when comparable trends in genotype 
frequencies at a locus are seen across progeny from unrelated families and also in offspring from a mass mating then that locus is less likely to be acting as a marker for more than a small portion of the chromosome tightly linked to the locus. Beaumont et al. $(1983,1988)$ have reported data in which significant variations in genotype frequencies at a number of loci occur between unrelated families of $M$. edulis. However, this is not the case at the Lap locus in the cultures described here where particular Lap genotypes occur consistently at lower or higher frequencies than expected.

There is strong genetic, physiological and biochemical evidence for direct selection at the Lap locus in relation to salinity (Hilbish and Koehn, 1985). However, the fact that Lap genotypes may have different fitnesses in relation to salinity does not rule out the possibility that linked loci may be involved in expressing the apparent differential fitnesses at the Lap locus detailed here. Lap alleles or genotypes may impose no fitness constraints at oceanic salinity and therefore may be effectively neutral in situations other than at low salinity. On the other hand, it seems probable that fitness constraints imposed by a locus, or loci closely linked to Lap would have effects over a range of salinities rather than being restricted to high salinity. Indeed effects are more likely under the stresses imposed by low salinity. It is difficult to reconcile this with the strong biochemical and physiological evidence which points to direct selection at the Lap locus in low salinities.

One further possibility stems from the work of Day et al. (1982) who demonstrated that the alcohol dehydrogenase $(\boldsymbol{A d h})$ locus is associated with a chromosome inversion polymorphism in the seaweed fly Coelopa frigida, such that consistent significant differences from Hardy-Weinberg expectations recorded at the $A d h$ locus are most likely due to the effect of linked loci within the inversion rather than to the $A d h$ locus itself. Mussels do not possess polytene chromosomes and therefore the presence of chromosomal inversions can best be detected by observing bivalents during meiosis. As far as we know, no systematic search has yet been undertaken for evidence of inversions during meiosis in mussels although mitotic chromosomes are beginning to be studied in more detail (Dixon and Clarke, 1982; Dixon et al., 1986). We cannot therefore rule out the possible association of the Lap locus with other linked loci within a chromosome inversion.

However, in the light of our earlier arguments, and in the absence of evidence of inversion poly- morphisms, we feel that there is a high probability that the apparent differences in fitness of Lap genotypes observed in our experiments are directly related to the Lap locus rather than to other closely linked loci in general.

The results clearly show that, in general, the $L a p^{94 / 96}, L_{a p}{ }^{94 / 98}$ and $L a p^{98 / 98}$ genotypes are more frequent, while the $L a p^{96 / 96}$ and $L a p^{96 / 98}$ are less frequent than expected. There is no suggestion in the data that the temperature regime to which a culture was exposed had any significant effect on genotype frequencies.

Using the genotype frequency data it is possible to estimate approximate relative fitnesses for the six common Lap genotypes. Estimates were obtained by calculating for each genotype, the mean percentage, over all families and the mass mating, by which observed frequencies deviated from expected frequencies. In the case of $L a p^{94 / 94}$, which was only present in the mass mating, the mean proportion of $\operatorname{Lap}^{94 / 94}$ individuals $(0.018+$ $/-0.010,95$ per cent $\mathrm{CI}$ ) over all cultures was not significantly different from the expected proportion $(0 \cdot 01)$. This genotype was therefore given a fitness of 1 . The relative fitnesses of all six Lap genotypes are given in Table 7 .

Table 7 Relative fitnesses of six Lap genotypes estimated from observed frequencies in up to 24 cultures from four single families and one mass mating

$\begin{array}{lllllll}\text { Lap genotype } & 94 / 94 & 96 / 96 & 98 / 98 & 94 / 96 & 94 / 98 & 96 / 98 \\ \text { Relative fitness } & 1.000 & 0.701 & 1.480 & 1.406 & 1.350 & 0.725\end{array}$

Hilbish and Koehn (1985) have proposed that a dominance model is most appropriate to explain their data on salinity related selection at the Lap locus in Long Island Sound. Individuals which were either homozygous or heterozygous for $\mathrm{Lap}^{94}$ exhibited similar biochemical and physiological phenotypes that were equally less fit compared to non- $\operatorname{Lap}^{94}$ genotypes. Furthermore, analyses of heterozygote deficiencies in genotype frequency data produced results which most closely fitted a selection model incorporating dominance. The relative fitnesses at the Lap locus estimated from our data would suggest overdominance rather than dominance, with regard to $\operatorname{Lap}^{94}$ and $\operatorname{Lap}^{96}$. $\operatorname{Lap}^{94}$ and $L a p^{96}$ heterozygotes had higher fitnesses than their respective homozygotes. On the other hand the $L a p^{98}$ heterozygote classes were less fit than the $L a p^{98 / 98}$ homozygote genotype and the intermediate fitnesses of the two heterozygotes indicates semi-dominance in the case of $\operatorname{Lap}^{98}$. 
Theoretical considerations (Crow, 1986) suggest that, if polymorphisms are maintained by selection, then dominance or semi-dominance will lead ultimately to fixation of particular alleles. Only overall overdominance can produce a stable equilibrium between all alleles. The dominance reported by Hilbish and Koehn (1985) for Lap ${ }^{94}$ at low salinity depends upon an annual influx of recruits from oceanic populations of mussels with a high frequency of $L a p^{94}$. Without such imput, $\operatorname{Lap}^{94}$ would theoretically become lost in estuarine populations of mussels. Beaumont et al. (1988) have suggested that there may be selection for, rather than against $\operatorname{Lap}^{94}$ during the larval stage at low salinity and that ontogenetic changes in fitness may be a feature in the maintenance of the Lap polymorphism. However, there is no suggestion of significant ontogenetic differences in fitness of Lap genotypes in the data presented here which were collected from cultures reared entirely at oceanic salinities.

Table 8 A model for selection at a locus with three alleles: $A_{1}, A_{2}$ and $A_{3}$

\begin{tabular}{lllllll} 
Genotype & $A_{1} A_{1}$ & $A_{2} A_{2}$ & $A_{3} A_{3}$ & $A_{1} A_{2}$ & $A_{1} A_{3}$ & $A_{2} A_{3}$ \\
Fitness & $W_{11}$ & $W_{22}$ & $W_{33}$ & $W_{12}$ & $W_{13}$ & $W_{23}$ \\
Frequency & $p_{1}^{2}$ & $p_{2}^{2}$ & $p_{3}^{2}$ & $2 p_{1} p_{2}$ & $2 p_{1} p_{3}$ & $2 p_{2} p_{3}$ \\
\hline
\end{tabular}

Using a standard model for selection at a locus with three alleles (table 8, Crow, 1986) it is possible to calculate what the frequencies of the three alleles would be at equilibrium in a panmictic population in Hardy-Weinberg equilibrium, assuming that the relative fitnesses proposed were applicable and were constant. The equilibrium frequencies of $\operatorname{Lap}^{94}\left(p_{1}\right), \operatorname{Lap}^{96}\left(p_{2}\right)$ and $\operatorname{Lap}^{98}\left(p_{3}\right)$ are calculated as follows (Crow, 1986).

$$
p_{1}=\frac{D_{1}}{D}, \quad p_{2}=\frac{D_{2}}{D} \quad \text { and } \quad p_{3}=\frac{D_{3}}{D}
$$

where

$$
\begin{aligned}
D_{1}= & \left(W_{12}-W_{22}\right)\left(W_{13}-W_{33}\right) \\
& -\left(W_{12}-W_{23}\right)\left(W_{13}-W_{23}\right) \\
D_{2}= & \left(W_{23}-W_{33}\right)\left(W_{12}-W_{11}\right) \\
& -\left(W_{23}-W_{13}\right)\left(W_{12}-W_{31}\right) \\
D_{3}= & \left(W_{13}-W_{11}\right)\left(W_{23}-W_{22}\right) \\
& -\left(W_{13}-W_{12}\right)\left(W_{23}-W_{12}\right)
\end{aligned}
$$

and $D_{1}+D_{2}+D_{3}=D . \quad W_{11}=$ fitness of $L a p^{94 / 94}$, $W_{12}=$ fitness of $L a p^{94 / 96}$ etc. A further quantity, $T$, is defined as

$$
T=W_{11}-W_{13}-W_{13}-W_{33} .
$$

For an equilibrium to be stable, $D_{1}, D_{2}$ and $D_{3}$ must be positive numbers and $T$ negative. Using the fitness values estimated here, the calculated allele frequencies at equilibrium are $L a p^{94}=0.632$, $L a p^{96}=0.332$ and $L a p^{98}=0.036$, but although $T$ is a negative number, $D_{1}, D_{2}$ and $D_{3}$ are also negative. In a panmictic population therefore, these relative fitnesses would lead eventually to fixation of one allele. In a stable equilibrium with three alleles, the mean fitness of the population should exceed that of any homozygote. If such a fit homozygote existed it would eventually become fixed in the population. The mean fitness at equilibrium, $\bar{W}$, can be calculated from the three allele model (table 8 ) using the expression:

$$
\begin{aligned}
\bar{W}= & p_{1}^{2} W_{11}+p_{2}^{2} W_{22}+p_{3}^{2} W_{33}+2 p_{1} p_{2} W_{12} \\
& +2 p_{1} p_{3} W_{13}+2 p_{2} p_{3} W_{23},
\end{aligned}
$$

where $p_{1}, p_{2}$ and $p_{3}$ are the allele frequencies at equilibrium. The calculated value for mean fitness $(\bar{W})$ at the Lap locus is $1 \cdot 148$ and this is lower than the fitness of the $L a p^{98 / 98}$ homozygote $(1 \cdot 480$, table 7). The model therefore predicts that a panmictic population with these relative fitnesses would lead to fixation of $L a p^{98}$. Looking again at the data used to estimate relative fitnesses, the greatest error is likely to have occurred with estimating the fitness of the $L a p^{98 / 98}$ genotype. Firstly, the estimate is derived from the mass mating cultures alone; no single families had this genotype. Secondly, Lap ${ }^{98 / 98}$ was expected at a low frequency $(0.09)$ in the mass mating progeny. Small differences between observed and expected numbers will have a greater effect on percentage differences than in genotypes expected at higher frequencies. The calculated relative fitness for the Lap ${ }^{98 / 98}$ genotype is probably, therefore an overestimate.

Nevertheless, the analysis suggests that the relative fitnesses of Lap alleles observed in these laboratory cultures would lead to fixation of $L a p^{98}$. Because all three alleles are in fact present in local wild populations, the relative fitnesses estimated from progeny reared in the laboratory must be different from those in the wild if the polymorphism is indeed maintained by selection.

This is perhaps not a surprising conclusion since laboratory conditions are obviously very different from the situation in the wild. What is unexpected, however, is the extent of genotype specific selection at the Lap locus in laboratory 
conditions which would be expected to be relatively non-stressful. One source of stress in laboratory culture may be nutrition. Algal cells are provided at higher than normal concentrations, but bacteria are very reduced in number and seawater filtration systems tend also to reduce the levels of free amino acids available for direct uptake by larvae or adults (Manahan, 1983; Manahan and Stephens, 1983). The enzyme coded at the Lap locus, an $\alpha$-aminoacyl peptide hydrolase (EC 3.4.11.-) (Young et al., 1979), is involved in the cleavage of $\mathrm{N}$-terminal aminoacids from polypeptides and therefore in the composition of the cellular free aminoacid pool (Moore et al., 1981). It is possible that a reduction in the amount of amino acids available for direct uptake by larval and juvenile mussels interacts with the cellular free aminoacid pool and therefore may be affected by genotype specific differences in biochemical activity at the Lap locus.

Other studies of laboratory-reared single families and mass matings of bivalves have also implicated direct or indirect selection at a number of enzyme loci (Beaumont et al., 1983, 1988; Adamkewicz, 1984; Hvilsom and Theisen, 1984; Mallet et al., 1985, 1986; Gaffney and Scott, 1984). Our results suggest that selection at a locus in the laboratory or in a hatchery condition may be very different from that found in nature and that the extrapolation of genetic data obtained in this way to the situation in the wild must be undertaken with caution. It must also be borne in mind that our data only deal with fitness to the juvenile stage and that changes in relative fitnesses may occur as the mussels grow. However, where data are available (tables 1 and 2), relative fitnesses of $L a p$ genotypes generally do not appear to change between spat and juvenile sampling within cultures, and, since mussels are sedentary and experience no major ecological changes while growing from juveniles to adults, we would not expect to observe major changes in relative fitnesses of the Lap alleles during this period.

Further suggestive evidence that Lap genotype specific mortalities in laboratory conditions may differ significantly from those in the wild comes from analysis of the overall deficiencies of $L a p$ heterozygotes. In wild populations of $M$. edulis and most other bivalves studied, Lap heterozygotes are generally deficient against Hardy-Weinberg expectations (Koehn et al., 1976; Skibinski et al., 1983; Colgan, 1987) and a number of explanations have been advanced to account for this observation (Zouros and Foltz, 1984; Colgan, 1987). Taking Lap genotype data from 37 samples of single family and mass mating cultures (excluding M4 where all Lap genotypes were heterozygous, but including cultures reared at varying salinities (Beaumont et al., 1988), 27 samples showed an excess of heterozygotes while only nine had too few heterozygotes. According to the null hypothesis that equal numbers of excesses and deficiencies are expected, the sign test confirms that there is a significant excess of heterozygotes in these laboratory cultures. This therefore contrasts with the deficiencies of Lap heterozygotes displayed by wild populations. However, direct comparison between heterozygote excesses caused by selection in laboratory conditions and heterozygote deficiences in wild populations may not be entirely valid since the latter phenomenon may be caused by factors other than selection (Zouros and Foltz, 1984). Although there is an apparent anomaly at the Lap locus, overall data from all loci studied do show a significant deficiency of heterozygotes in samples taken at the juvenile stage (unpublished data). Thus the overall trend in laboratory cultures is similar to the situation in the wild and the Lap locus may be unusual in this respect.

Acknowledgements We are grateful to the Natural Environment Research Council who funded this study under Grant no. GR3/5286 to A.R.B. We also thank Dr A. B. Yule for useful discussions and an anonymous referee for helpful criticism of the manuscript.

\section{REFERENCES}

ADAMKEWICZ, L., TAUB, S. R. AND WALL, J. R. 1984. Genetics of the clam Mercenaria mercenaria. II. Size and genotype. Malacologia, 25, 525-533.

AHMAD, M. AND HEDRICK, P. W. 1985. Electrophoretic variation in the common mussel, Mytilus edulis: random association of alleles at different loci. Heredity, 55, 47-51.

BEAUMONT, A. R., BEVERIDGE, C. M. AND BUDD, M. D. 1983. Selection and heterozygosity within single families of the mussel, Mytilus edulis (L.) Mar. Biol. Letts., 4, 151-161.

BEAUMONT, A. R., BEVERIDGE, C. M., BARNETT, E. A., BUDD, M. D. AND SMYTH-CHAMOSA, M. D. 1988. Genetic studies of laboratory reared Mytilus edulis. I. Genotype specific selection in relation to salinity. Heredity, 61, 389-400.

COLGAN, D. J. 1987. Deficits of heterozygotes in relation to selective interactions between loci in the mussels Brachidontes rostratus and Xenostrobus pulex. Heredity, 59, 355-362.

CROW, J. F. 1986. Basic Concepts in Population, Quantitative and Evolutionary Genetics. W. H. Freeman \& Company, New York, 273 pp.

DAY, T. H., DOBSON, T., HILliER, P. C., PARKIN, D. T. AND CLARKE, B. 1982. Associations of enzymic and chromosomal polymorphisms in the seaweed fly Coelopa frigida. Heredity, 48, 35-44. 
DIXON, D. R. AND CLARKE, B. 1982. Sister chromatid exchange: a sensitive method for detecting damage caused by exposure to environmental mutagens in the chromosomes of adult Mytilus edulis. Mar. Biol. Letts., 3, 163-172.

DIXON, D. R., McFADZEN, I. R. B. AND SISLEY, K. 1986. Heterochromatic marker regions (nucleolar organisers) in the chromosomes of the common mussel Mytilus edulis (Mollusca: Pelecypoda). J. exp. mar. Biol. Ecol,, 97, 205212.

GAFFNEY, P. M. AND SCOTT, T. M. 1984. Genetic heterozygosity and production traits in natural and hatchery populations of bivalves. Aquaculture, 42, 289-302.

HILBISH, T. J., DEATON, L. E. AND KOEHN, R. K. 1982. Effect of an allozyme polymorphism on regulation of cell volume. Nature, 298, 688-698.

HILBISH, T. J. AND KOEHN, R. K. 1985. Dominance in physiological phenotypes and fitness at an enzyme locus. Science, 229, 52-54.

HVILSOM, M. M. AND THEISEN, B. F. 1984. Inheritance of allozyme variations through crossing experiments with the blue mussel, Mytilus edulis L. Hereditas, 101, 1-7.

KOEHN, R. K. 1985. Adaptive aspects of biochemical and physiological variability. In Gibbs, P. E. (ed.) Proc. 19th Eur. Mar. Biol. Symp. Cambridge University Press, pp. 425-441.

KOEHN, R. K., MILKMAN, R. AND MITTON, J. B. 1976. Population genetics of marine pelecypods. IV. Selection, migration and genetic differentiation in the blue mussel Mytilus edulis. Evolution, 30, 2-32.

LEVINTON, I. S. AND KOEHN, R. K. 1976. Population genetics of mussels. In Bayne, B. L. (ed.) Marine Mussels, Their Ecology and Physiology, Cambridge University Press, pp. 357-384.

MALLET, A. L., ZOUROS, E., GARTNI:R-KEPKAY, K. E. AND FREEMAN, K. R. 1986. Genetics of growth in blue mussels: family and enzyme-heterozygosity effects. Mar. Biol., 92, 475-482.
MALLET, A. L., ZOUROS, E., GARTNER-KEPKAY, K. E., FREE MAN, K. R. AND DICKIE, L. M. 1985. Larval viability and heterozygote deficiency in populations of marine bivalves: evidence from pair matings of mussels. Mar. Biol., 87, 165-172.

MANAHAN, D. T. 1983. Nutritional implications of dissolved organic material for laboratory culture of pelagic larvae. In Berg, C. J. Jr. (ed.) Culture of Marine Invertebrates. Selected Readings. Hutchinson Ross Pub. Co., Pennsylvania, USA, pp. 179-192.

MANAHAN, D. T. AND STEPHENS, G. C. 1983. The use of high performance liquid chromatography to measure dissolved organic compounds in bivalve aquaculture systems. Aquaculture, 32, 339-346.

MOORE, M. N., KOEHN, R. K. AND BAYNE, B. L. 1980. Leucine aminopeptidase (aminopeptidase-I), N-acetyl- $\beta$-hexosaminidase and lysosomes in the mussel, Mytilus edulis L. in response to salinity changes. J. Exp. Zool., 214, 239-249.

SKIBINSKI, D. O. F., BEARDMORE, J. A. AND CROSS, T. F. 1983. Aspects of the population genetics of Mytilus (Mytilidae; Mollusca) in the British Isles. Biol. J. Linn. Soc., 19, $137-$ 183.

SOKAL, R. R. AND ROHLF, F. J. 1981. Biometry, 2nd edn. W. H. Freeman and Company, San Francisco, USA, 859 pp.

YOUNG, P. J. W., KOEHN, R. K. AND ARNHEIM, N. 1979. Biochemical characterisation of "LAP" a polymorphic aminopeptidase from the blue mussel Mytilus edulis. Biochem. Genet., 17, 305-324.

ZOUROS, E. AND FOLTZ, O. W. 1984. Possible explanations of heterozygote deficiency in bivalve molluscs. Malacologia, $25,583-591$. 